\title{
Implicações da Certificação pela NP 4427:2004 na Função Recursos Humanos
}

\author{
Ana Martins, ESEIG \\ Dora Martins, ESEIG
}

Este estudo tem como objetivo central compreender as mudanças na função recursos humanos após a certificação do sistema de gestão de recursos humanos de uma empresa no âmbito da Norma Portuguesa 4427:2004 - "Sistemas de gestão de recursos humanos - requisitos".

Foi utilizada a metodologia qualitativa, com recurso ao estudo de caso único numa empresa portuguesa certificada no âmbito da NP 4427:2004. O processo de recolha de dados incidiu na análise documental e na realização de entrevistas a todos os colaboradores com data de vínculo à empresa anterior à data de obtenção desta certificação.

Os resultados sugerem terem ocorrido mudanças na atuação da gestão de recursos humanos da empresa, concretamente o desenvolvimento de uma dimensão mais estratégica através de práticas de recursos humanos sistematizadas e focalizadas no desenvolvimento das pessoas. Este estudo também mostrou que o conhecimento do âmbito de intervenção da função recursos humanos é diferentemente conhecido e valorizado pelos representantes da gestão organizacional e os restantes colaboradores.

Palavras-chave: Gestão de Recursos Humanos; Função Recursos Humanos; Práticas de Gestão de Recursos Humanos; NP 4427:2004. 